\title{
What Kind of Pedagogy Do We Need to Address Extremism and Terror?
}

\author{
M. Ayaz Naseem \\ Associate Professor \\ Department of Education \\ Concordia University \\ ayaz.naseem@education.concordia.ca \\ Adeela Arshad-Ayaz \\ Assistant Professor \\ Department of Education \\ Concordia University \\ Adeela.ayaz@education.concordia.ca
}

\begin{abstract}
One of our primary objectives of this paper is to examine the veracity of the modern usage of 'extremism' in order to broaden the understanding of this phenomenon and relatedly also open up the space in which solution to extremism can be found. Understanding contemporary extremism as a crisis in education, our second objective is to propose a critical counter extremism pedagogy that can make visible vital connections between extremism and the wider interlinked political, economic, social, and cultural processes at the global level.
\end{abstract}

\section{Introduction}

Oxford Dictionaries Online (2016) defines extremism as "holding of extreme political or religious views". However, in contemporary parlance extremism is almost always used to connote Islamic extremism. Solutions/interventions based on such an understanding focus on only one aspect and kind of extremism i.e. acts of terror by Muslims. Furthermore, most solutions, directly or indirectly stem from a national security/law-and-order perspective. In this paper, we analyze dominant perspectives and the veracity of the contemporary usage of "extremism" and propose to broaden the understanding of this phenomenon. We aim to describe how broadening the understanding of "extremism" can be used both as a call for deepening critical engagements in education as well as a bridge for discussions of "extremism" in ways that move conversations into new realms and seek solutions. Understanding contemporary extremism as a crisis in education (Haider, 2005), the second objective of this paper, is to propose a critical counter extremism pedagogy that can make visible vital connections between extremism and the wider interlinked political, economic, social, and cultural processes at the local and global levels. 
Our contention in doing so is that Islamic extremism is but only one form of extremism, and it is intricately linked to other types of extremism that are all a product of modernity. In other words, extremism in its contemporary iteration should not only be understood as relating to going back to fundamentalist teachings/thoughts/ ideologies. Rather, it must be understood as a product of conditions and politics of modernity. Thus, solutions to extremism (of all kinds) have to be searched within the conditions of modernity. We also contend that there is a need to contextualize the interconnectedness of various physical and symbolic extremisms leading to violence at various levels in the globalized world. A narrow, singular focus such as religion or ideology forecloses the space to examine intricate linkages that are essential to developing a comprehensive understanding of this phenomenon. We, however, must state at the outset that by broadening the terminology of "extremism" and identifying systemic linkages we, by no means, condone religious or any other forms of extremist acts resulting in varying degrees of violence.

We have organized the discussion in three sections. In the first section, we attempt to broaden the definition of extremism by identifying "extreme" ideologies, behaviors, and perpetrations that are usually not considered a part of the mainstream definitions of extremism. These include (but are not limited to) hate-based extremism, gender-based extremism, neo-liberal/economic extremism, neo-conservative extremism, and epistemic extremism or knowledge imperialism (Naseem \& Arshad-Ayaz, 2012). In the second section, we examine the causes of extremism in the overall context of modernity and one of its main manifestations namely the national security state. In this context we scrutinize the military-industrial-knowledge complex, the predatory neo-liberal capitalism, and the widespread disenfranchisement that results from these conditions in the creation of spaces in which violence is and can be carried out in various forms including extremism carried out in the name of religion(s). In the final section, we turn our attention to finding solutions to the problem of extremism(s). We shift the focus from an essentially militaristic and law-and-order framework grounded in the national security state (NSS) to look for more sustainable and longer lasting approaches to counter extremisms of varying kinds. We do so by focusing on pedagogy, both as space as well as a strategic toolkit, to combat extremism. We, thus, raise and try to answer the question: what kind of pedagogy is needed to counter extremism? We conclude the discussion by proposing a pedagogical framework to promote "conscientiz[action]" as a counter-extremism pedagogy.

\section{Understanding Extremism: Opening the Field}

What is extremism? In a generalized sense, extremism refers to the adoption and employment by individuals and groups, of severe means including violence to achieve certain ends. This understanding of extremism disrupts "the kind of order which Max Weber called the state's monopoly on violence" (Davydov, 2015, p. 53). As a norm, it is almost always the state (or those who wield power in its name) that has the power to ascertain what is extreme, who is the extremist, and what is extremism (Davydov, 2015). In other words, it is the state that has the power to name, define, and designate people, groups, situations, and behaviors as extreme and extremist. 
It is important to note that the state has always had this naming power. However, in contemporary times, the dynamics and mechanisms through which this naming exercise takes place have changed. While previously extremists were those who, through extreme means challenged the power of the monarch or the state, now any challenge to the established global politico-economic interests that may or may not be under the sole domain of a single state is considered and consequently called extremism. What is also different is that the "system" itself might display extreme tendencies (i.e. adoption and employment of severe/extreme means) but these tendencies individually or as a whole are not considered extremist.

For example, if we take loss of life (killing) or destruction of livelihood as cases of extremism then displacement of people, loss of life in police custody, police brutality, killing of civilians termed as collateral damage, loss of life and property resulting from preemptive drone attacks, can all be labeled as extreme acts and thus "extremism". However, these are almost never called as such because of the power that only the state has to name. Another difference is that while previously it were individuals and groups that were usually labeled as extremists (for example, Carlos, PLO, the Red Brigade, Bader-Meinhof, etc.) now whole populations (Muslims), states (Iran, North Korea) and even cultures and religions are labeled as extremists. Three conditions that lend the power to naming practices are: One, the state/military/economic power, two, an unquestioning population, and three, a hegemonic knowledge system.

The colonial powers used the complex interconnections of military might, unquestioning populations, and hegemonic knowledge systems to reap unlimited profits from the colonial project. All three elements feed into one another in a cyclical way. In our opinion, however, it was hegemonic knowledge systems which gave the colonial state immense power to "name" the colonized people as barbaric, savage, undeveloped, infants, etc. to carry on the colonial project in the name of helping the underdeveloped develop and civilizing the uncivilized. The modern (neocolonial) state continues to use the three elements mentioned above. However, learning from the experience of colonization where populations decoded many tactics as "state endorsed extremism" and ultimately questioned and challenged the colonial state, the contemporary neo-liberal state had to come up with a collective strategy which would help it to retain the power of naming. The discourse of inevitability of globalization coupled with neo-liberal ideology provides the modern states the space to continue with their neocolonial powers to selectively name, some people, situations, cultures, religions, and knowledge systems as extremists.

Such power to name does four things: First, it creates an 'other' that is almost always outside the (dominant) system and is hell bent on disrupting and/or destroying the state endorsed system. Second, solutions focus on countering, stopping, and destroying the real or assumed perpetrators or "extremists." The solutions do not address the causes of "extremist" actions. Third, the focus shifts away from the system itself towards certain individuals, groups, religions, regions, ethnicities, behaviors, and issues. Finally, and most importantly, interlinkages between the cause and effect are obscured. 
We contend that contemporary extremism has to be understood in its immediate historical context i.e. the context of modernity (or late modernity) and not in ancient history, cultures, and/or scriptures of certain people. Extremism, in this sense, is intrinsically linked to the dominant politico-economic system namely the confluence of neoconservatism, the neo-liberal economic system, and the national security state. We also believe that there is a need to open up and disrupt the contemporary articulation and understanding of extremism, to understand the context, discursive constitution, as well as the interlinkages between various forms of extremism that feed on each other. In other words, without bringing into focus the extremist tendencies and features of the predatory neo-liberal capitalism and the reactionary neo-conservative extreme, it is hard to understand the causes of and thus solutions to what is labeled as "Islamic extremism" and the related violence. In the next section, we briefly discuss the national security state and the predatory neo-liberal economic system as contexts and sources of extremism.

\section{State Terrorism: The National Security State and Global Social Inequality as Sources of Extremism}

As mentioned earlier, the onset and entrenchment of the predatory neo-liberal economic model and its political twin, neo-conservatism, has resulted in, among other things, a mutational change in the nature of the state. Since 9-11 the national security state has replaced any remaining vestiges of the erstwhile welfare state as a framework within which the relationship between the state and its subjects were earlier defined and understood. Hardt and Negri (2005) call it the transition from the welfare state to warfare state. In this framework, the national security is the main nodal point around which all other signs are defined and understood.

According to the Oxford Essential Dictionary of the US Military (2016), the national security state (NSS) is "a post World War II state in which nearly all aspects of politics, economics, intellectual, and social life are dominated by considerations of national defense and the drive to maintain a defense establishment capable of protecting the state against all comers." The NSS framework functions through what Deukmedjian (2013), in the context of security surveillance, calls "thresholds of tolerance" (p. 55). The NSS sets the tolerance threshold for objects and events beyond which they are intolerable. It is at this juncture that the apparatuses of security (state) come into motion through "practices of preparedness, preemption, disruption, resilience, containment, displacement, or elimination" (p. 55). One might add to this list of functions the practices of naming. In the context of extremism, the NSS defines and sets the threshold of tolerance not in relation to the object/event (the Islamic extremism/acts of terror) but rather in relation to other extremist objects and events (neo-liberal economic system and neo conservatism) by tolerating the existence of the latter and dealing with them not through security surveillance but through disciplinary surveillance. For example, the NSS is willing to tolerate police brutality on black youth, loss of life and property through transnational corporations' (TNCs) "externalizing machines", mass displacements because of war and environmental degradation. However, the NSS sets a low tolerance threshold for some 
types of extremism (real and perceived Islamic extremism), thus setting into motion practices of preparedness, preemption, disruption, and elimination.

Furthermore, the national security state negotiates with the subjects of the erstwhile welfare state in order to bring them to its fold. In exchange for provision of security against the real or perceived perpetrators (that are named by the NSS itself), it asks for and takes away social welfare privileges, privacy, and freedoms that the subjects previously were entitled to. This allows the national security state to divest itself of both, the function of maintaining "equilibrium on the regulatory and social dimensions" (Deukmedjian, 2013, p. 65), and lately of the function of providing security to its subjects. The former is manifested in the processes of market deregulation to a point where the state is under the supervision of the market (Foucault, 2008, cited in Deukmedjian, 2013, p. 65) and the latter is manifested in privatizing the provision of security to private contractors such as Blackwater/Academi. On both counts, the power of the state to name enemies plays a major role in bringing benefits to those who profit from the supremacy of the market. On the political side, the neo-conservative rhetoric, especially its stance for an expansionist and interventionist foreign policy abroad and a limited role for government (state) in regulating the market domestically, is not only situated in the national security state framework but also strengthens it.

However, economic and political mechanisms of the NSS, in our opinion, cannot function without what Armitage (2006) calls the "hyper militarized knowledge production" (p. 220). Such knowledge production is both, the cause and effect of the national security state framework. Armitage defines hyper militarized knowledge production as an educational system/regime that produces militarized graduates who are, then, "brought together with the aid of new information and communication technologies (ICTs) such as the internet" (p. 221). Educational institutions such as the universities, according to Armitage are "engaged in militarization of knowledge, namely, in the militarization of facts, information, and abilities obtained through the experience of education" (p. 221). Calling them hyper militarized knowledge production factories, Armitage includes in them "...schools, colleges, research centers, think tanks and so on" (p. 222). Hyper militarized knowledge production factories produce knowledge and knowledge-subjects that redefine foundational political ideas such as sovereignty, democracy, freedom, and the state-subject relationship, among others. They also produce knowledge by which the national security state exercises the naming practices; a neoorientalism of sorts. Hyper militarized knowledge production is closely linked to the neoliberal economic practices through what Giroux (2007) calls the trilogy of forces that shape contemporary education, namely, "patriotic correctness, consumerism, and militarization" (p. 4). These forces, according to Giroux are not only shaping educational systems but are also articulating and inculcating the primacy of an undemocratic social order. Educational institutions under the hyper militarized knowledge production regime operate as a training ground for the state, its military machine, and the corporations thus obscuring the fundamental functions of critical knowledge production namely democratic and social justice values. According to Giroux (2007), "combined with the political onslaught from the neoconservative political right the educational institutions are being stripped of their pedagogical functions in the name of patriotic correctness" (p. 8). 
The narrative of the national security state goes something like this: the state with its power to name, in its anxiety to safeguard its monopoly over means of violence invokes the discourse of security (we are under attack; our value system is under attack). It justifies this bogey (the security concerns) through the hyper militarized knowledge produced in and through the educational system to an unquestioning, militarized population. In doing so, it obscures the extremist nature of the national security state as well as that of the predatory neo-liberal economic order. It also obfuscates extremism in the disciplinary apparatuses unleashed on marginalized groups within the society; extremism of a brutal inequality domestically and globally; the extremism of consumption patterns that drive the environmental change that in turn displaces large populations as environmental refugees. The hyper militarized knowledge production also results in large-scale disenfranchisement both domestically (within the national security state) and globally. Domestically, disenfranchisement results in heightened anxiety expressed in xenophobia (harsh attitudes towards refugees, migrants) that the national security state capitalizes on to promote its militaristic adventures. On the other hand, xenophobic attitudes among the dominant groups result in heightened uncertainty in immigrant and refugee populations. There is a sizable body of research that identifies uncertainty as a "correlate of and ...precondition of extremism" (Hogg, Kruglanski, \& van den Bos, 2013, p. 407; also see contributions by leading psychologists in the Journal of Social Issues, 69(3), 2013). Xenophobia in the dominant group combined with a culture of violence in society and education serves as a "powerful factor that fosters extremism" (Davydov, 2015, p. 58). Similarly, uncertainty in the immigrant and refugee groups combines with adverse socio-economic opportunities and conditions, identity dynamics, and dissatisfaction with the political system to create conditions that nurture extremist tendencies (Davydov, 2015).

It is imperative that a system that fosters extremism be countered at all levels. However, we argue that education should be at the forefront of countering the extremist system and resultant "named" and "unnamed" extremisms. In the following section, we propose, in broad strokes, the kind of pedagogy that can counter extremist tendencies in both the dominant as well as in the minority groups.

\section{What Kind of Pedagogy Do We Need to Address Extremism and Terror?}

From the preceding discussion, it is clear that there is neither one form of extremism nor one source of it. Extremism originates, exists, and is reproduced on a global scale and is very much a part of the globalized world in which we live. Extreme actions range from systemic extremism inherent in and intrinsic to the predatory neo-liberal economic order to the more overtly political and religious extremism that results from the political and religious ideologies of the "right".

Instead of looking at extremist behavior and focusing on extremist acts only as a result of ideological, religious, cultural, and ethnic tensions, extremism needs to be located within large-scale insecurity and disequilibrium caused by neo-liberal economic policies and the politics of current times. It is important to make vital connections between "named 
extremist acts" and the uncertainty, instability, and unjust conditions resulting from the predatory neo-liberal capitalism. It is also important to examine "the act of naming" by the NSS in maintaining its neo-colonial powers which are not only applied to the "outsiders" or the "others" but have now been selectively extended upon NSS's own subjects. Examples can be found in labeling and portraying some social movements for justice, environmental protection groups as eco-terrorists, Occupy Wall Street, or Idle No More, in the same light as violent extremist acts resulting in terror and violence. It is imperative to contrast acts and behaviors that get named as "extreme" with similar acts and behaviors that do not get named as "extreme" by the NSS, to question, challenge, and change a system which creates "extremes".

It is thus important to keep in focus the multitude of causal factors (of extremism) as well as their manifestations as we seek pedagogical solutions. In the following space we posit a critical counter extremism pedagogy, the main tenets of which are:

- Transdisciplinarity

- Transnationality

- Engagement with excluded knowledge systems

- Conscientiz[action]

The critical counter-extremism pedagogy is situated in the critical pedagogy tradition as articulated by Paulo Freire and other critical pedagogists. One of the cardinal tenets of Freirean critical pedagogy is the ability to "read the world VS read the word". The former refers to first moving beyond and then outrightly rejecting the $a$ political, dehistoricized and decontextualized technical knowledge devoid of ethical considerations and philosophical curiosity in favor of a historicized and contextualized political knowledge of the world around us including the forces, mechanisms, and structures that are oppressive. It also entails exhuming political meanings and interlinkages in cultural and political texts. The critical counter-extremism pedagogy contends that through collaborative meaning making and deconstruction of socio-political and economic structures, emancipatory cultural texts can be generated which will make explicit to the publics the complicity of socio-economic and political structures in the production of real and symbolic violence. Such clarity is required to be able to "name" the oppression inherent in the structure, in political, economic, cultural, even religious realms, and in relationships between the dominant and the marginalized groups and individuals. Reading the world is, in a way, an exercise in appropriating the "naming" power that the state and the dominant groups possess. It is an exercise in disrupting the power and in empowerment.

Transdisciplinarity. The reading of the world in today's interconnected and networked society cannot take place within the confines of a single discipline. To be able to read the world, a transdisciplinary pedagogy with prowess to create awareness of the living conditions, structural oppressions, etc., is required. Without a true transdisciplinary pedagogy, deep interlinkages between seemingly benign processes (financial regulations, lending practices, credentialization, etc.) cannot be understood. Yet, it is these seemingly 
innocent interlinkages that lead to marginalization (through consumption patterns, for example). It is, thus, important to be able to locate the disciplinary location of the oppressive texts and to be able to connect them to other disciplinary locations.

With the fragmentation of pedagogy into disciplinary silos (in the name of creating experts and expertise), the pedagogical subjects are unable to connect important dots. For example, to get a complete picture learners need to connect the effects of one set of practices (financial regulations, lending practices) with another (consumption patterns), and connect these with yet another set of practices (environmental degradation leading to forced migrations). Such understanding is necessary to comprehend the growing inequity that results in uncertainty and instability for a large number of people across the globe. Similarly, we can take the example of seemingly benign lifestyles in one part of the world that put pressures and demand an increasing supply of raw materials, labor, and resources in other parts of the world. Maintenance of what is defined as "good standard of living" leads towards a race to exploit resources and creating unjust social and economic conditions in some parts of the world that result in uncertainty and instability.

The fragmented/segmented knowledge that is imparted to the students contributes to a concealed domination and hegemony where the subjects see nothing wrong in these violent symbolic processes and start to consider them normal. In fact, so normalized is the symbolic violence that not only do the subjects not see any harm in them but also are willing to support these structures, processes, and practices when the national security state asks them to in the name of national security.

Critical counter extremism pedagogy is predicated on transdisciplinarity. It calls for teaching, learning and understanding phenomena such as extremism from multiple disciplinary perspectives instead of narrow disciplinary perspectives (security, politics, strategic/military studies). The multidisciplinary foci are needed to impress upon the learners to connect seemingly unrelated dots; connect the exegesis of global finance, for example, to political, ecological, social, and other discourses that construct and help understand the phenomena such as extremism and terrorism. Transdisciplinary counter extremism pedagogy will equip the students with critical abilities to move the focus away from single explanation causes and develop an understanding of interlinked underlying causes because of which extremist behavior takes shape.

Transnationality. A second important distinguishing feature of the critical counter extremism pedagogy is transnationality. As Arshad-Ayaz (2011) notes the causes of most issues today including extremism and terrorism cannot be understood, taught, and/or addressed within the context of the individual nation-state or single cultural and societal contexts. This argument is predicated on the recognition that the world is more intricately linked than we normally recognize. The acts of individuals and groups are not confined to individual nation states. Their actions are "produced and reproduced by discourses, institutions, and practices that cut across national boundaries and have varying influences on people living in diverse areas of the world" (Arshad-Ayaz, 2011, p. 71). To understand extreme acts of a particular group, individuals, or religious affiliations we need to extend our pedagogical analysis beyond the Nation State, its practices and Journal of Contemporary Issues in Education, 2016, 11(1), pp. 6-18 
policies, to explore the global spaces that have been opened up for causing inequality and extreme actions.

The concept of transnationality is important to critical counter extremism pedagogy because contemporary subjects live in a state of transnationality where turbulence in global finance and politics outside of their countries of origin and/or residence makes them vulnerable. A case in point is the Arab Spring that is widely attributed to people's dissatisfaction with the tyrant and corrupt regimes in the Middle East and North Africa Region (MENA), or to the role that modern technologies such as social media played in these uprisings. We contend that it were the global upheaval in wake of the 2008 recession and volatility in the global financial markets that led to widespread food shortages, rise in inflation, and the general economic downturn for the people in the MENA region. This turbulence was the real cause behind the volatility in the region (Arshad-Ayaz, 2014; also see Howard \& Hussain, 2013). Relatedly, the events in the MENA region had a direct impact on how the diaspora of and migrant population from the countries in this region were viewed by the people in the host countries in North America and Europe. Migrants' affiliation to and the images of their countries and societies of origins often permeated their identities in the host countries (Arshad-Ayaz, 2011). Transnationally situated counter extremism pedagogy shifts the focus away from the exclusivity of the singular national, cultural, and societal contexts to find and understand the causes of violence at the level of transnational forces, institutions, policies, and processes. It also seeks to order/arrange these forces, institutions, and processes in a transnational framework where the interrelated mechanisms and working is exposed. Thus, it moves the focus away from single-issue explanations (Muslims are violent because of their scriptural teachings and/or their faith) and asks the students to look for multi-factor explanations combining systemic factors with those at the societal, group, or individual levels. By moving away from single-factor explanations, the transnationally situated counter extremism pedagogy also has the potential to bring into focus the excluded knowledge systems.

Engagement with excluded knowledge systems. Thirdly, critical counter extremism pedagogy seeks to be inclusive of knowledge frameworks that have been orientalised (Said, 1978) by the western knowledge regimes. Marginalization, and in some cases outright annihilation of other knowledge systems (ways of knowing) is in itself an act of (extreme) violence that is seldom recognized (Smith, 2012). In its modern iteration, it can be called the latest phase of imperialism; the knowledge imperialism (Naseem \& ArshadAyaz, 2012). A remarkable net effect of the marginalization of other knowledge systems is the inability of the students to understand the epistemic locations from which the "othered"/marginalized people come from and talk to us. Such inability makes the students understand these people solely through the constructs of the dominant ("othering") knowledge system rooted in the Enlightenment framework that has been instrumental in the marginalization (colonization) in the first place.

Critical counter extremism pedagogical framework is grounded in the need and desire for a dialectical and dialogical relationship between the dominant knowledge system and the hitherto excluded and/or marginalized knowledge systems. However, it insists that the 
dialogue must be on a level playing field with a moral sincerity, humility, and a genuine desire to understand, include, and respect the genealogical, moral, historical, and intellectual roots and contributions of each knowledge system in a spirit of discovery and respect. Also on the table in such a dialogue are assumptions of moral superiority and historical and contextual veracity of the western knowledge system without prejudice.

In this dialogue Avicenna regains his own self as Ibne Sina; al-Gazel comes back as AlGhazali; Rhazes (re)-becomes Al-Razi (Faruqi, 2006). Such a dialogue imagines bringing together Galileo and Newton in conversations with Al-Hazen and Nasir uddin al-Tusi; Kant, Satre, and Weber acknowledge Ibne-Rusd, Muhammad Al-Ghazali, Rumi, and Kalidas (Faruqi, 2011); Tagore locks intellectual horns with Durkheim.

Conscientiz[action]. Following in the footsteps of Frantz Fanon (conscienciser) and Paulo Freire (conscientização) we posit conscientiz[action] as the fourth tenet of critical counter extremism pedagogy. Conscientiz[action] refers to the final stage of conscientização that results in direct action to disrupt the power of established dominant discourses, structures, and regimes inherently present in social, political cultural, and educational environments. The popular and mainstream understanding of "critical pedagogy" in the western context, be it diversity education, multicultural education, race education, or cultural pluralism, is based on the assumption that we do not understand the culture of the other. However, mere knowledge about the other will not change the extreme structures, policies, and laws that control and civilize (subjugate) the "other". In other words, a true critical counter extremism pedagogical framework must make sure that conscientization leads to "consientiz-action". This is a type of action where the focus is on equity and justice. The goal is to disrupt the space that allows the roots of extremist actions to spread.

The action is this sense could range from deviating from the prescribed texts (syllabi, textbooks, learning materials) to questioning established practices and truths through direct individual and collective action (e.g. boycotting goods, practices, messages that promote consumerist, militaristic, and securitized practices). In the spirit of popular education and social movement education conscientiz[action] entails a reciprocal reflexion between action and consciousness-raising where both inform each other but where the latter is the starting point for realizing the former. In this sense, action is not (only) an end product but also a means to consciousness-raising. Action and consciousness-raising are thus in a mutually (re) formative fluid relationship where each informs the other through rhizomatic associations and connections. Conscientiz[action] thus understands action and consciousness-raising through the principle of $a$ signifying rupture (Deleuze \& Guattari, 1980). When action and consciousness-raising are hindered (broken) by the dominant discourses (of neo-liberalism, the national security state, neoconservatism, orientalism), they regenerate along old or newer lines. 


\section{Conclusions}

Following Haider (2005, in Armitage, 2005, p. 230) we can safely say that contemporary extremism as discussed above is a crisis in education as much as it is a crisis in societal, national, and international security. Contemporary educational systems under the national security state and the neo-liberal economic regime militarize and securitize the state, its subjects, and the relationship between the two. Due to this overwhelming obsession with security dynamics, contemporary education obscures vital connections between extremism, and systemic, societal, economic, cultural, and political causes of extremism. Thus, most of the solutions sought, developed, and employed to counter extremism are grounded in law and order and security approaches. In the light of the preceding discussion, we propose a critical counter extremism pedagogy that has the capacity and prowess to demystify these vital connections. This pedagogy must be interdisciplinary, situated in a transnational space, must be able to bring in and engage with excluded knowledge systems, and finally, must lead to action directed at a just and inclusive political, economic, and intellectual change. It should be able to insist on the primacy of alternative conceptions and appreciation of the relationship between education and the wider social, political, and economic order. Critical counter extremism pedagogy strives to fit into Comenius' notion of omnis, omnia, omnino - to teach everything to everybody thoroughly, in the best possible way. 


\section{References}

Armitage, J. (2005). Beyond hypermodern militarized knowledge factories. Review of Education, Pedagogy, and Cultural Studies, 27(3), 219-239. http://dx.doi.org/10.1080/10714410500228884

Arshad-Ayaz, A. (2011, Spring). Making multicultural education work: A proposal for a transnational multicultural education. Canadian Issues: A Publication of the Association for Canadian Studies (pp. 71-75).

Arshad-Ayaz, A. (2014). Religion, technology and social change: Representations of Muslim world in academic analyses of the role of social media in the Arab Spring. TARBIYA- Journal of Education in Muslim Society, 1(2). http://dx.doi.org/10.15408/tjems.v1i2.1264.

Davydov, D. G. (2015). The causes of youth extremism and ways to prevent it in the educational environment. Russian Social Science Review, 56(5), 51-64. http://dx.doi.org/10.1080/10611428.2015.1115295

Deleuze, G., \& Guattari, F. (1988). Rhizome. In A thousand plateaus: Capitalism \& schizophrenia (pp. 3-25). London: Athlone.

Deukmedjian, J. (2013). Making sense of neoliberal securitization in urban policing and surveillance. Canadian Review of Sociology, 50(1), 52-73. http://dx.doi.org/10.1111/cars. 12002

Faruqi, S. (2006). Islam, democracy, and development. Selangor: IPENA/UITM.

Faruqi, S. (2011, November 12). Western intellectual imperialism in Malaysian legal education. Economic and Political Weekly, 46(46), 55-60.

Giroux, H. (2007). The university in chains: Confronting the military-industrialacademic complex. Boulder, London: Paradigm Publishers.

Haider, A. (2005). Seven theses on the anti-war movement and student resistance. interactivist, Info Exchange. Available at https://zcomm.org/znetarticle/seventheses-on-the-anti-war-movement-and-student-resistance-by-asad-haider/

Hardt, M., \& Negri, A. (2005). Multitude: War and democracy in the age of empire. New York: Penguin.

Hogg, M., Kruglanski, A., \& van den Bos, K. (2013). Uncertainty and the roots of extremism. Journal of Social Issues, 69(3), 407-418. http://dx.doi.org/10.1111/josi.12021

Howard, P., \& Hussain, M. (2013) Democracy's fourth wave? Digital media and the Arab Spring. (Series: Oxford Studies in Digital Politics). New York, NY: Oxford. http://dx.doi.org/10.1093/acprof:oso/9780199936953.001.0001

Naseem, M. A., \& Arshad-Ayaz, A. (2012). Education and democracy: Recasting the role of education in exploring democratic possibilities in the Global South. In A. A. Abdi, \& P. R. Carr (Eds.). Educating for democratic consciousness: Counterhegemonic possibilities. Netherlands: Peter Lang Publishing.

Oxford Dictionaries online (2016). "Extremism", accessed February 10, 2016, on http://www.oxforddictionaries.com/definition/english/extremism

Oxford Essential Dictionary of the US Military (2016). "National Security State", accessed February 10, 2016, on oxfordindex.oup.com/view/10.1093/oi/authority.20110803100224575 
Said, E. (1978). Orientalism. New York: Pantheon Books.

Smith, L. T. (2012). Decolonizing methodologies: Research and indigenous peoples.

New York, NY: Zed Books. 